\title{
馬蹄腎に合併した海綿腎の 1 例
}

\section{福島県立医科大学泌尿器科学教室 \\ 入澤 千晴 山口 脩 白岩康夫 \\ 入澤病院泌尿器科}

菊池悦啓入澤俊 氏

山形大学医学部泌尿器科学教室

入澤千晶

\section{A CASE OF MEDULLARY SPONGE DISEASE ASSOCIATED WITH HORSESHOE KIDNEY}

\author{
Chiharu Irisawa, Osamu Yamaguchi and Yasuo Shiraiwa \\ Department of Urology, Fukushima Medical College \\ Yoshinobu Kikuchi and Syunshi Irisawa \\ Department of Urology, Irisawa Hospital \\ Chiaki Irisawa \\ Department of Urology, School of Medicine, Yamagata University
}

A 60-year-old man visited our hospital with complaints of micturition pain and interruption of urinary stream.

X-ray examinations were performed, showing no bladder and urethral stone. However, KUB revealed bilateral multiple renal stones. Excretory urography showed a horseshoe kidny and a concentration of the contrast medium in the ectatic tubules at the pyramidal apices. Calculi were also located in these ectatic tubules.

Thus, we considered that this was a very rare case of meudllary sponge disease associated with horseshoe kidny.

So far there has been no case report of medullary sponge disease with horseshoe kidny in our country.

Key words: horseshoe kidney, medullary sponge disease

\begin{abstract}
要旨: 症例は60歳, 男子. 突然の排尿時痛, 尿線中絶及び軽度の膀脱刺激症状を訴兄来院. 尿道膀胱造 影で明かな結石陰影は認められなかったが,腹部単純撮影にて両側腎部に多発性の小結石陰影を認めた。 更に，排泄性腎孟造影で腎長軸が下方で交差する所見と腎錐体先端部の拡張した集合管内に貯留した造 影剤を認めた．X 線 CT では椎体前面で両腎下極が癒合する所見を認めた。従って, 本症例は馬蹄腎に 海綿腎が合併した稀な 1 例と診断した。

臨床上, 馬蹄腎及び海綿腎は比較的よく経験するが, 両者の合併例は本邦では報告されておらず本症 例が第 1 例目と思われた。
\end{abstract}

キーワード：馬蹄腎, 海綿腎

緒 言
馬蹄腎は腎原基の発生の過程で両側の腎下極が正中
に近ついて癒合して起こるとされ, 同時に尿道下裂,
停留睪丸など泌尿器系の先天異常や水腎症, 結石など
を合併することが多いと言われている. また, 腎は先
天性あるいは後天性に囊胞形成を見ることが多く, 中
でも腎髄質の囊胞性疾患である海綿腎は, 結石を伴う ことが多くしばしば経験される，最近，我々は馬蹄腎 に合併した両側海綿腎の 1 例を経験したので報告す る.

患者：60歳, 男子.
症例 
図 1 両側腎部に多発性の小結石陰影を認める.

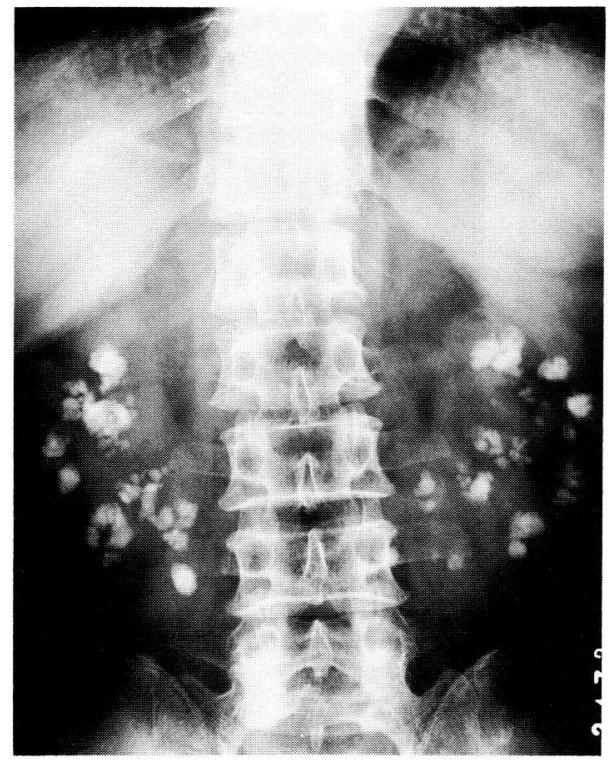

主訴：排尿時痛，尿線中絶.

既往歴：6 年前, 腹痛にて某病院を受診した時海綿 腎を指摘された。

家族歴：特記すべきこと無し。

現病歴：1989年 9 月 11 日, 突然の排尿時痛, 尿線中 絶及び軽度の膀脱刺激症状を訴えて来院した。

来院時現症：体格中等度, 栄養良. 胸部に異常所見 なく，腹部触診にて両側腎及び腫瘤を触知せず，口ブ シング徵候なし，前立腺，精囊及び外性器にも異常を 認めなかった。

血液・生化学検査所見: 赤血球 466 万 $/ \mathrm{mm}^{3}$, 白血球 $5,600 / \mathrm{mm}^{3}$, Hb $14.2 \mathrm{~g} / \mathrm{dl}$, Ht $43 \%$, ESR $16 / 40 \mathrm{~mm}$. TP $6.5 \mathrm{~g} / \mathrm{dl}$, GOT 16IU/l, GPT $11 \mathrm{IU} / l$, LDH 172 $\mathrm{U} / l, \quad \mathrm{BUN} 12.7 \mathrm{mg} / \mathrm{dl}, \mathrm{Cr} 0.8 \mathrm{mg} / \mathrm{dl}, \mathrm{UA} 4.5 \mathrm{mg} /$ dl, Na $141 \mathrm{mEq} / l, \mathrm{~K} 3.6 \mathrm{mEq} / l, \mathrm{Cl} 98 \mathrm{mEq} / l$, Ca $9.4 \mathrm{mg} / \mathrm{dl}, \mathrm{P} 4.0 \mathrm{mg} / \mathrm{dl}$. PTH-C $0.3 \mathrm{ng} / \mathrm{ml}$.

尿所見：蛋白 (一)，糖(一)，沈渣にて赤血球20～50/ hpf, 白血球 $20 \sim 30 / \mathrm{hpf}, \mathrm{pH} 6.3$, Ca $270 \mathrm{mg} / \mathrm{day}, \mathrm{P}$ $1,200 \mathrm{mg} / \mathrm{day}$, 苳酸 $16.2 \mathrm{mg} / \mathrm{day}$.

心電网所見：異常なし。

$\mathrm{X}$ 線検査所見：尿道膀胱造影にて明かな結石像は 認められなかったが，腹部単純撮影で両側腎部に多発 性の小結石陰影を認めた(図 1)。排泄性腎盂造影にて 腎昷腎杯の軽度の抬張，尿管の腎前面からの下降及び 腎長軸の尾側での交差を認めた。更に，払張した集合
図 2 腎の長軸は尾側で交差して扣り馬蹄腎が疑われ る。をた，拡張した集合管内に造影剤と小結石を認 め海綿腎と思われる。

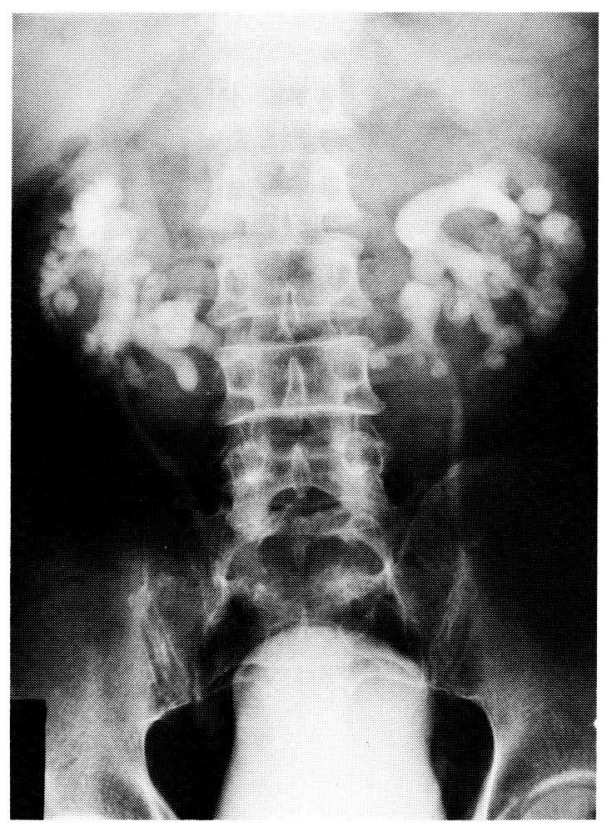

図 3 椎体前面で腎下極が癒合しており馬蹄腎であ る.

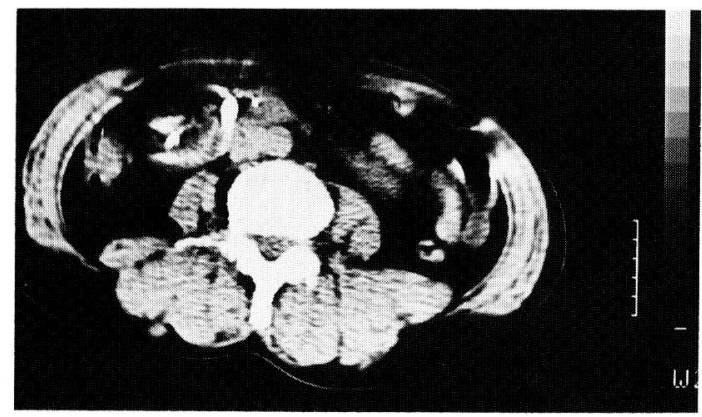

管に造影剂が貯留する pyramidal blush と, 同部に一 致した多発性の小結石陰影を認めた（図 2).X 線 CT 検査にて椎体前面で腎下極が癒合している所見を認め た(図 3 ).

経過：以上より本症例は馬蹄腎に海綿腎が合併した 稀な 1 例であり, 腎結石の一部が下降し尿道に嵌頓, 尿線中絶や膀胱刺激症状を来たし, 更に軽い膀朕炎を 併発したものと判断した。

水腎症が軽度で腎機能も正常なので, まず抗生剂及 び消炎鎮痛剂を投与して膀胱刺激症状を軽快させ，結 
石の排出があれば成分分析をすることとし外来通院で 経過を観察することにした。

来院翌日，自宅で排尿した時異物の排出感があり， その後愁訴は消失した。

定期的に X 線検查を行なっているが著しい変化は 無く, 結石の排出も認めていない.

\section{考察}

尿路系藏器の発生異常による奇形は珍しいものでは なく, 中でも馬蹄腎は比較的多い疾患であり Campbell ${ }^{11}$ は一般人の $0.25 \%$ に また柿崎ら 2 は泌尿 器系患者 48,887 例中 23 例 $(0.21 \%)$ にみられたとして いる。一方, 海綿腎もしばしば経験されるが Palubinskas ${ }^{3}$ は排泄性腎孟造影を施行した 2,456 例中 14 例 $(0.56 \%)$ ，宮内 ${ }^{4)}$ 女同様に 6,520 例中 36 例 (0.55\%) に認めたとしている.

馬蹄腎は無症状で経過することも少なくないが腰部 痛や血尿で発見されることが多い，また，尿流通障害 による水腎, 二次的感染, 結石形成などを続発するほ か囊胞腎5), ウイルムス腫瘍(6), 腎癌7), その他の泌尿器 系奇形を合併することもある。しかし海綿腎を合併し た症例は我々が検索し得た範囲では1987年, Lambrianides $ら^{8)}$ が血尿を主訴とした50歳の女性を報告 した 1 例だけであり, 本邦では認められなかった。

さて，海綿腎は血尿や結石症状で見つかることが多 く, Abeshouse ら 9)は報告例を集計し136例中88例 $(65 \%)$ ， Harrison ら ${ }^{10}$ は46例中43例 $(93 \%)$ ，広 野ら $\left.{ }^{11}\right)$ は68例中 56 例 $(82 \%)$ に結石を合併していたと述 べている。 また, 尿酸性化障害, 濃縮力低下, 高カル シウム尿を認めたとの報告もあるが一定の見解はな く, 感染や結石による閉塞などの合併症がなければ腎 機能は保たれるとされている12).

馬蹄腎の治療は水腎, 感染, 結石など二次的病変に 対するものが主であり, 症状が強ければ半腎切除術や 狭部切断術, 腎孟尿管形成術, 結石摘出術などが行わ れる。海綿腎に対しては高尿酸血, 或は高尿酸尿があ ればアロプリノールを, 高カルシウム尿があればサイ アザイドを投与すれば結石予防に有効とも言われてい る.

本症例は，馬蹄腎と結石を伴った海綿腎を合併して いるため, 結石の増加増大, それに伴ら尿流障害の増 覀や二次的感染の危険性がより高く, 将来の腎機能低 下が懸念される。しかし，幸いにして現在は腎機能が
正常であり, 二次的病変も結石以外は軽く, 高尿酸血 症, 高カルシウム尿もなく, 尿の $\mathrm{pH}$ や尿中苳酸排泄量 も正常なので充分注意しながら経過観察することとし た。もし，結石の排出があれば成分を分析し，適した 薬剤の投与を行ら予定である。

\section{結語}

60歳, 男性の馬蹄腎に海綿腎が合併した極めて稀な る 1 例を経験したので報告した。

\section{文献}

1) Perlmutter, A.D., Retik, A.B. and Bauer, S.B. : Anomalies of the upper urinary tract. in Urology, Campbell, M.F., 5th ed., p. 1687, Saunders Co., Tokyo, 1986.

2）柿崎 勉：腎・腎孟及び尿管の先天性奇形. 日本泌 尿器科全書, p. 33, 金原出版, 南江堂, 東京, 1960.

3) Palubinskas, A.J.: Renal pyramidal stracture opacification in excretory urography and its relation to medullary sponge kidney. Radiol., 81, 963-970, 1963.

4）宮内大成, 伊藤晴夫, 村上光右, 山口邦雄, 臼井利 夫, 甘粕 誠, 桜山由利, 島崎 淳: 海綿腎の臨床 的研究. 日泌尿会誌, 76, 540-545, 1985.

5) Correa, R.J. and Paton, R.R.: Polycystic horseshoe kidney. J. Urol., 107, 802, 1976.

6) Gay, B.B. Jr., Dawes, R.K., Atkinson, G.O. Jr. and Ball, T.I. Jr.: Wilmus tumor in horseshoe kidneys: Radiologic diagnosis. Radiol., 146, 693-697, 1983.

7）横田 崇, 山口 脩, 坂上善成, 深谷保男, 白岩康 夫：馬蹄腎に合併した腎細胞癌の 1 例．泌尿器外 科, 2, 925-928, 1989 .

8) Lambrianides, A.L.B.Sc. and John, D.R. : Medullary sponge disease in horseshoe kidney. Urology, 29, 426-427, 1987.

9) Abeshouse, B.S. and Abeshouse, G.A.: Sponge kidney : A review of the literature and a report of five cases. J. Urol., 84, 252-265, 1960.

10) Harrison, A.R. and Rose, G.A.: Medullary sponge kidney. Urol. Research, 7, 197-207, 1979.

11）広野晴彦, 中神義三, 陳 水：海綿腎一統計的観 察を中心に. 臨泌, 26, 1051-1057, 1972.

12) Higashihara, E., Nutahara, K., Tago, K., Ueno, A. and Niijima, T.: Renal function studies in cystic renal disease. Jnp. J. Nephrol., 23, 1021-1026, 1981.

（1990年 5 月 2 日受理） 